\title{
Activation of Metabotropic Glutamate Receptors Increases CAMP Accumulation in Hippocampus by Potentiating Responses to Endogenous Adenosine
}

\author{
Danny G. Winder and P. Jeffrey Conn \\ Department of Pharmacology and Neuroscience Program, Emory University School of Medicine, Atlanta, Georgia 30322
}

\begin{abstract}
Metabotropic glutamate receptors (mGluRs) are coupled to effector systems through GTP-binding proteins (G-proteins) and appear to mediate slow synaptic responses in the CNS. Although mGluR-mediated increases in phosphoinositide hydrolysis have been well characterized, other mechanisms for signal transduction employed by mGluRs are poorly understood. We recently reported that the selective mGluR agonist 1 -aminocyclopentane-1S,3R-dicarboxylic acid $(1 S, 3 R-A C P D)$ increases cAMP accumulation in rat hippocampal slices. We have now investigated the mechanisms involved in this response. A number of G-protein-linked receptors that are not directly coupled to adenylate cyclase increase CAMP accumulation by potentiating CAMP responses to other agonists. Furthermore, previous studies suggest that glutamate increases CAMP accumulation by a mechanism that is dependent upon the presence of endogenous adenosine. Therefore, we tested the hypothesis that 1S,3R-ACPD-stimulated increases in CAMP accumulation in rat hippocampal slices are dependent upon the presence of endogenous adenosine and are mediated by an mGluR that potentiates CAMP responses to other agonists. We found that adenosine deaminase abolished 1S,3R-ACPD-stimulated CAMP accumulation whereas the adenosine uptake blocker dipyridamole enhanced this response. Additionally, adenosine receptor antagonists blocked mGluR-mediated increases in CAMP accumulation with potencies that were highly correlated with their potencies at $A_{2}$ adenosine receptors. Furthermore, we performed a series of studies that suggest that $1 S, 3 R$-ACPD activates an mGluR subtype that potentiates responses to agonists of other receptors that are coupled to adenylate cyclase and that $1 S, 3 R-A C P D-$ stimulated increases in CAMP accumulation in hippocampal slices are mediated by potentiation of the cAMP response to low levels of endogenous adenosine that are continuously present extracellularly.
\end{abstract}

[Key words: metabtropic glutamate receptor, trans-1-aminocyclopentane-1,3-dicarboxylic acid (trans-ACPD), CAMP, adenosine, xanthine, hippocampus]

\footnotetext{
Received May 27, 1992; accepted July 21, 1992.

We thank Dr. James A. Monn for the gift of $1 R, 3 S$-ACPD and Dr. Kenneth $P$. Minneman for helpful discussions and critical reading of an earlier manuscript. This work was supported by NIH Grant NS28405-01.

Correspondence should be addressed to Dr. P. Jeffrey Conn, Department of Pharmacology, Rollins Research Building, Emory University School of Medicine, Atlanta, GA 30322.

Copyright (C) 1993 Society for Neuroscience $0270-6474 / 93 / 130038-07 \$ 05.00 / 0$
}

Receptors for the excitatory neurotransmitter glutamate have been classified into two broad families. Ionotropic glutamate receptors are coupled directly to cation channels and mediate fast excitatory synaptic responses at various synapses throughout the CNS (for reviews, see Collingridge and Lester, 1989; Monaghan et al., 1989). The more recently discovered metabotropic glutamate receptors (mGluRs) are linked to second messenger systems via GTP-binding proteins (G-proteins) and participate in generation of slow synaptic responses and modulation of neuronal excitability (for reviews, see Schoepp et al., 1990; Conn and Desai, 1991). To date, the most well characterized mGluR subtype is coupled to activation of phosphoinositide hydrolysis. However, relatively little is known about the other mechanisms of signal transduction employed by the mGluRs.

A major advance in our understanding of mGluRs came with the recent cloning of four mGluR subtypes from rat brain (designated mGluR 1-mGluR4) (Houamed et al., 1991; Masu et al., 1991; Tanabe et al., 1992). Studies of cloned mGluRs in expression systems such as Xenopus oocytes (Houamed et al., 1991; Masu et al., 1991; Tanabe et al., 1992) and Chinese hamster ovary cells (Aramori and Nakanishi, 1992) have yielded some information regarding the second messenger systems activated by mGluRs. However, biochemical responses to receptors expressed in such systems may not always reflcct the second messenger systems employed by receptors in cells in which they are normally expressed. Thus, to gain a clear understanding of the signal transduction mechanisms employed by mGluRs, it will be important to characterize the responses to activation of native receptors and compare the pharmacological properties of those responses to those of the cloned receptors.

The recent discovery of selective mGluR agonists such as trans-1-aminocyclopentane-1,3-dicarboxylic acid (trans-ACPD) (Palmer et al., 1989; Desai and Conn, 1990) has greatly facilitated the study of the effects of mGluR activation in brain slices and primary cell cultures. We recently reported that the active isomer of trans-ACPD, 1 -aminocyclopentane-1 $S, 3 R$-dicarboxylic acid ( $1 S, 3 R$-ACPD), increases cAMP accumulation in rat hippocampal slices (Winder and Conn, 1992). This increased cAMP accumulation appears to be mediated by an mGluR since it is not blocked by ionotropic receptor antagonists such as D2-amino-5-phosphonovaleric acid (D-AP5) and 6-cyano-2,3-dihydroxy-7-nitroquinoxaline (CNQX), but is blocked by a putative $\mathrm{mGluR}$ antagonist L-2-amino-3-phosphonoproprionic acid (L-AP3) (Winder and Conn, 1992). However, the mechanisms involved in $1 S, 3 R$-ACPD-stimulated increases in cAMP accumulation are not known. 
Previous studies indicate that excitatory amino acids (EAAs) other than $1 S, 3 R$-ACPD increase cAMP accumulation in rat brain slices by a mechanism that is dependent on the presence of endogenous adenosine (Shimizu et al., 1974; Schmidt et al., 1977; Bruns et al., 1980). Since mGluRs had not been discovered when these studies were performed, it was concluded that EAA-stimulated increases in cAMP accumulation were mediated by activation of ionotropic glutamate receptors, subsequent depolarization, and release of endogenous adenosine. However, it is now clear that agonists of a number of G-protein-linked receptors increase cAMP levels by potentiating cAMP responses to other receptors rather than by direct coupling to adenylate cyclase (Magistretti and Schorderet, 1985; Pilc and Enna, 1986; Johnson and Minneman, 1987; Garbarg and Schwartz, 1988; Schaad et al., 1989). It is possible that adenosine-dependent increases in cAMP accumulation are mediated by activation of receptors belonging to this class and that activation of these receptors increases cAMP levels by potentiating responses to extracellular adenosine. Indeed, basal levels of extracellular adenosine in brain have been estimated to be in a range near that required for activation of the adenylate cyclase-coupled $\mathrm{A}_{2}$ adenosine receptors (Fredholm et al., 1984). Thus, we performed a series of studies in which we tested the hypothesis that the mGluR-mediated increase in cAMP accumulation is dependent on the presence of endogenous adenosine and involves activation of an mGluR subtype that potentiates cAMP responses to other agonists.

\section{Materials and Methods}

Increases in cAMP accumulation were measured using a modification of the method of Shimizu et al. (1969) as described in Johnson and Minneman (1986). This method involves measurement of agonist-induced accumulation of ${ }^{3} \mathrm{H}$-cyclic AMP in rat hippocampal slices prelabeled with ${ }^{3} \mathrm{H}$-adenine. Briefly, cross-chopped hippocampal slices ( 350 $\times 350 \mu \mathrm{m})$ were prepared from male Sprague-Dawley rats (150-200 $\mathrm{gm}$ ) and incubated in Kreb's bicarbonate buffer (KRB; $108 \mathrm{~mm} \mathrm{NaCl}$, $4.7 \mathrm{~mm} \mathrm{KCl}, 2.5 \mathrm{~mm} \mathrm{CaCl}_{2}, 1.2 \mathrm{~mm} \mathrm{MgSO}_{4}, 1.2 \mathrm{~mm} \mathrm{KH}_{2} \mathrm{PO}_{4}, 10 \mathrm{~mm}$ glucose, and $25 \mathrm{~mm} \mathrm{NaHCO}$ ), at $37^{\circ} \mathrm{C}$ for $15 \mathrm{~min}$. Tissue was washed and incubated for $40 \mathrm{~min}$ in $15 \mathrm{ml}$ of $\mathrm{KRB}$ containing $30 \mu \mathrm{Ci}{ }^{3} \mathrm{H}$ adenine (American Radiolabelled Chemicals, St. Louis, MO) and $6 \mu \mathrm{M}$ unlabeled adenine. After several rinses with warm KRB, $25 \mu$ l aliquots of gravity packed slices were transferred to incubation tubes and incubated for $15 \mathrm{~min}$ with appropriate drugs (final volume, $0.5 \mathrm{ml}$ ). The reaction was terminated with $50 \mu \mathrm{l} 77 \%$ trichloroacetic acid, and $25 \mu \mathrm{l}$ of $10 \mathrm{~mm}$ cyclic AMP was added as a carrier. The tissue was homogenized and centrifuged $(15 \mathrm{~min}, 17,000 \times \mathrm{g})$, and $25 \mu \mathrm{l}$ of the supernatant was removed for determination of total radioactivity incorporated into the tissue. ${ }^{3} \mathrm{H}$-cyclic AMP in the remaining supernatant was isolated by sequential elution through Dowex and then alumina columns. The results were expressed as a percentage conversion of total radioactivity to ${ }^{3} \mathrm{H}$-cyclic AMP. All incubations were at $37^{\circ} \mathrm{C}$ under an atmosphere of $\mathrm{O}_{2}, \mathrm{CO}_{2}$ in a shaking water bath.

Materials. $1 S, 3 R$-ACPD, $1 S, 3 S$-ACPD, D-AP5, L-AP3, and CNQX were purchased from Tocris Neuramin (Essex, UK). $1 R, 3 S$-ACPD was a generous gift from Dr. James A. Monn (Lilly Research Laboratories). Theophylline, caffeine sodium benzoate, prostaglandin $\mathrm{E}_{2}\left(\mathrm{PGE}_{2}\right)$, isoproterenol, 3-isobutyl-1-methylxanthine (IBMX), vasoactive intestinal peptide (VIP), and 2-chloroadenosine (2-CA) were purchased from Sigma. Adenosine deaminase (ADA) was purchased from Boehringer Mannheim. 8-Cyclopentyl-1,3-dipropylxanthine (DPCPX), xanthine amine congener (XAC), and Ro20 1724 were purchased from Research Biochemicals Inc.

\section{Results}

Consistent with our previous report (Winder and Conn, 1992), incubation of cross-chopped hippocampal slices with $1 S, 3 R$ ACPD resulted in a concentration-dependent increase in cAMP accumulation. The increase in cAMP accumulation upon ad-

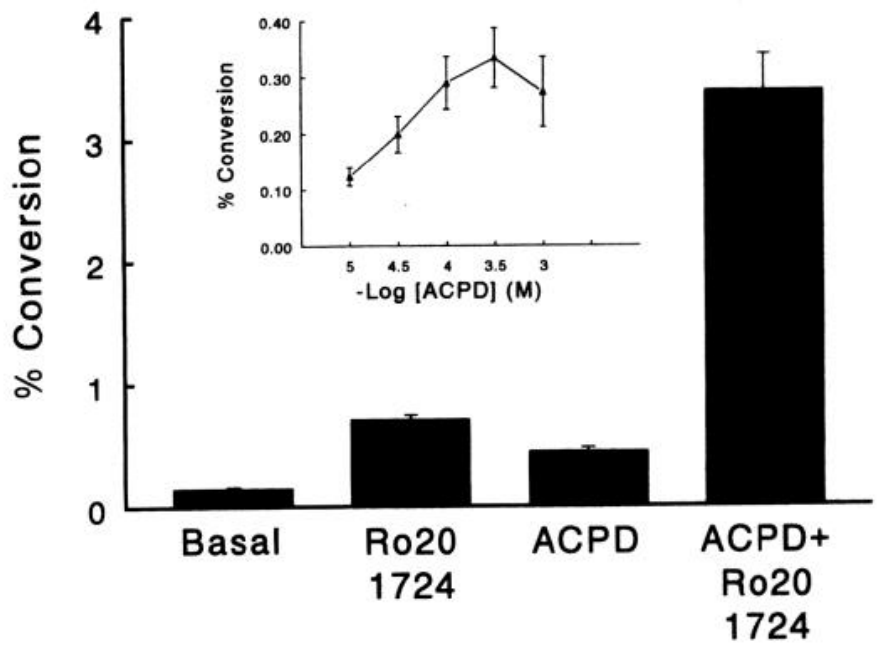

Figure 1. Effect of Ro20 $1724(200 \mu \mathrm{M})$ on conversion of ${ }^{3} \mathrm{H}$-adenine to ${ }^{3} \mathrm{H}$-cAMP induced by $1 S, 3 R$-ACPD $(100 \mu \mathrm{M})$. The inset shows dose response of $1 S, 3 R$-ACPD-stimulated cAMP increases as previously reported (Winder and Conn, 1992). Each bar and point represent the mean $( \pm$ SEM) of three separate experiments, each done in triplicate. $A C P D, 1 S, 3 R$-ACPD.

dition of $100 \mu \mathrm{M} 1 S, 3 R$-ACPD was potentiated in the presence of the cyclic nucleotide phosphodiesterase inhibitor Ro20 1724 $(200 \mu \mathrm{M})$ (Fig. 1), suggesting that phosphodiesterase inhibition is not a mechanism of $1 S, 3 R$-ACPD-stimulated cAMP increases.

\section{IS,3R-ACPD-stimulated increase in CAMP accumulation is inhibited by ADA and enhanced by blockade of adenosine uptake}

The hypothesis that adenosine mediates $1 S, 3 R$-ACPD-stimulated cAMP increases in hippocampal slices was tested by measuring the effect of $1 S, 3 R$-ACPD $(100 \mu \mathrm{M})$ on cAMP accumulation in the presence of ADA. ADA inhibited $1 S, 3 R$ ACPD-stimulated cAMP increases in a concentration-dependent manner with an $\mathrm{IC}_{50}$ of approximately $0.5 \mathrm{U} / \mathrm{ml}$ (Fig. 2). ADA at a concentration of $10 \mathrm{U} / \mathrm{ml}$ completely inhibited cAMP increases stimulated by $1 S, 3 R$-ACPD. The concentration of ADA needed to inhibit $1 S, 3 R$-ACPD-stimulated cAMP accumulation was similar to the concentration previously shown to inhibit the cAMP response to glutamate (Schmidt et al., 1977; Bruns et al., 1980).

Another prediction of the hypothesis that $1 S, 3 R$-ACPDstimulated cAMP accumulation is mediated by endogenous adenosine is that blockade of adenosine uptake should enhance the cAMP response to $1 S, 3 R$-ACPD. We measured the effect of the adenosine uptake blocker dipyridamole on $1 S, 3 R$ ACPD-stimulated increases in cAMP accumulation. Dipyridamole $(10 \mu \mathrm{M})$ induced a slight $(\approx 1.5 \times$ basal $)$ increase in cAMP accumulation when added alone and markedly potentiated the response to $1 S, 3 R$-ACPD $(100 \mu \mathrm{M})$ (Fig. 3).

\section{$1 \mathrm{~S}, 3 \mathrm{R}-A C P D$-stimulated increase in cAMP accumulation is dependent on activation of $A_{2 b}$ adenosine receptors}

Adenosine stimulates cAMP accumulation in rat hippocampal slices by activating the $A_{2 b}$ subtype of adenosine receptor (Bruns et al., 1986; Lupica et al., 1990; Olah and Stiles, 1992). Thus, it is possible that activation of mGluRs increases cAMP accumulation by increasing $\mathrm{A}_{2 \mathrm{~b}}$-mediated effects of adenosine. 


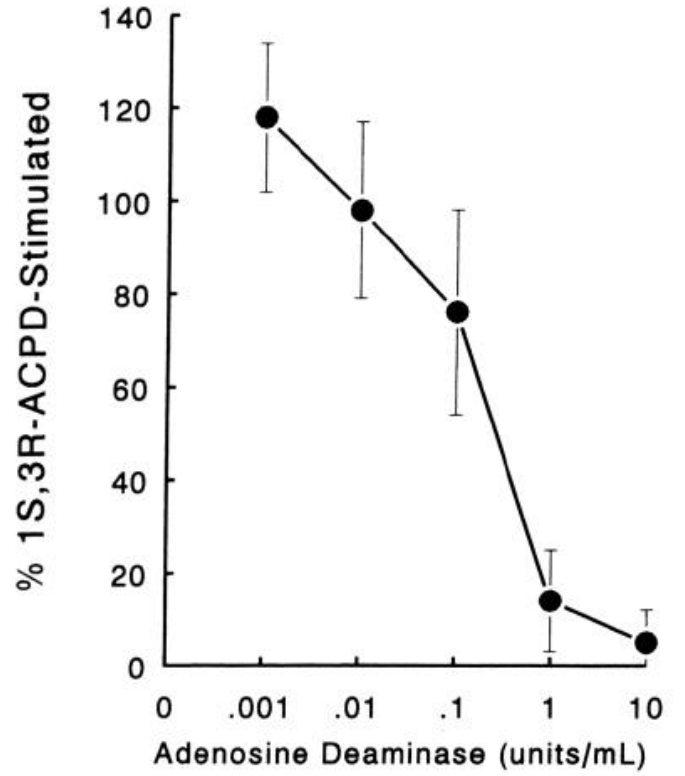

Figure 2. Effect of ADA on $1 S, 3 R$-ACPD-stimulated cAMP accumulations. Incubations are in the presence of $100 \mu \mathrm{M} 1 S, 3 R$-ACPD. In the absence of ADA, conversion of ${ }^{3} \mathrm{H}$-adenine to ${ }^{3} \mathrm{H}-\mathrm{cAMP}$ elicited by $100 \mu \mathrm{M} 1 S, 3 R$-ACPD was $0.2888 \pm 0.027 \%$, while basal conversion was $0.1323 \pm 0.012 \%$. Data are presented as percentage of this maximal response to $1 S, 3 R$-ACPD. Each point represents the mean $( \pm \mathrm{SEM})$ of four separate experiments, each done in triplicate.

Therefore, we next tested the hypothesis that the $1 S, 3 R$ ACPD-stimulated increase in cAMP accumulation was dependent upon activation of $\mathrm{A}_{2 \mathrm{~b}}$ adenosine receptors. This was accomplished by determining the effects of adenosine receptor antagonists with a range of affinities at $\mathrm{A}_{2}$ adenosine receptors on cAMP responses to $1 S, 3 R$-ACPD and adenosine. In these studies, we used concentrations of $1 S, 3 R$-ACPD $(100 \mu \mathrm{M})$ and adenosine $(30 \mu \mathrm{M})$ that elicited cAMP responses of similar magnitudes. The responses to these concentrations of $1 S, 3 R$-ACPD and adenosine were $207 \pm 18 \%$ and $232 \pm 30 \%$ of basal respectively. The adenosine receptor antagonists used in these experiments included a number of xanthine derivatives (IBMX, DPCPX, XAC, caffeine, and theophylline) and one non-xan-

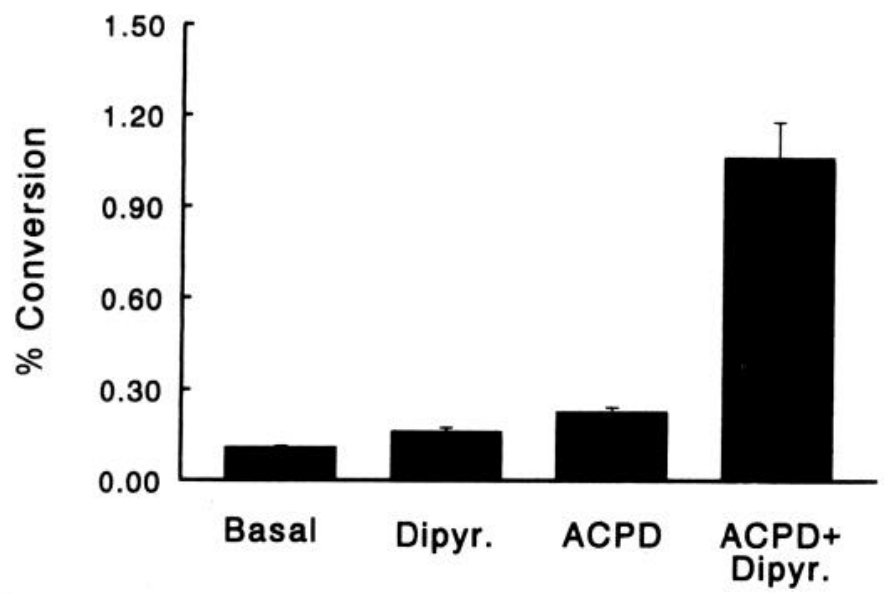

Figure 3. Effect of dipyridamole $(10 \mu \mathrm{M})$ on $100 \mu \mathrm{M} 1 S, 3 R$-ACPDstimulated cAMP accumulation. Data are presented as percentage conversion of ${ }^{3} \mathrm{H}$-adenine to ${ }^{3} \mathrm{H}$-cAMP. Each bar represents the mean $( \pm \mathrm{SEM})$ of three experiments, each done in triplicate. Dipyr., dipyridamole; $A C P D$, $1 S, 3 R$-ACPD.
A
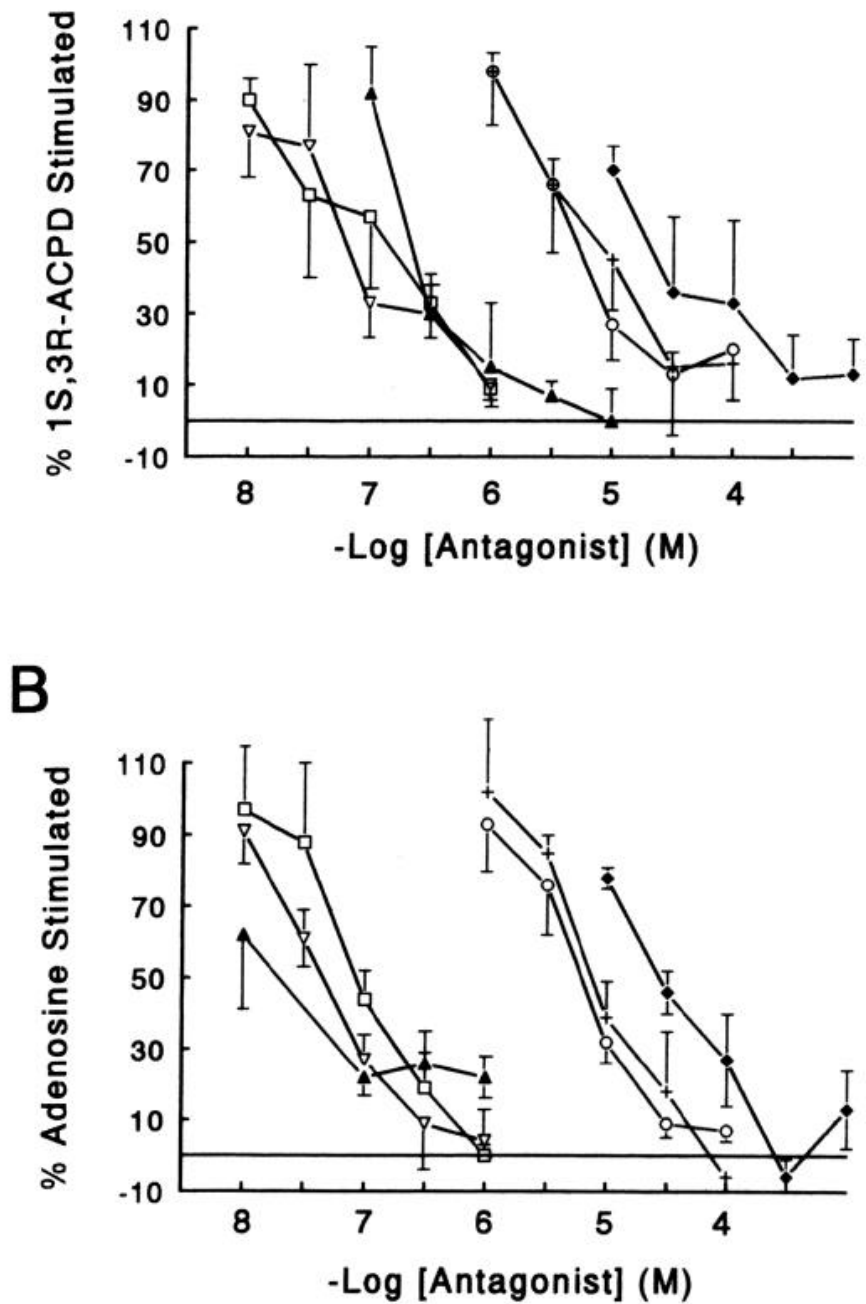

Figure 4. Effects of adenosine receptor antagonists on $100 \mu \mathrm{M} 1 S, 3 R$ ACPD-stimulated $(A)$ and $30 \mu \mathrm{M}$ adenosine-stimulated $(B)$ cAMP accumulations. Each point represents the mean $( \pm$ SEM) of three or four separate experiments, each done in triplicate. $1 S, 3 R$-ACPD $(100 \mu \mathrm{M})$ and adenosine $(30 \mu \mathrm{M})$ in the absence of antagonist stimulated cAMP accumulations of $207 \pm 18 \%$ and $232 \pm 30 \%$ of basal, respectively. Data are presented as percentage of the response to $1 S, 3 R$-ACPD or adenosine in the absence of antagonists. $\square$, XAC; $\nabla$, CGS 15943; $\Delta$, DPCPX; O, IBMX; +, theophylline; $\diamond$, caffeine.

thine (CGS 15943). IBMX inhibits cyclic nucleotide phosphodiesterases at the concentrations needed to block adenosine receptors (Choi et al., 1988). Thus, experiments with this antagonist were performed in the presence of the phosphodiesterase inhibitor Ro20 $1724(200 \mu \mathrm{M})$. All antagonists tested inhibited both $1 S, 3 R$-ACPD-stimulated and adenosine-stimulated cAMP accumulation in a concentration-dependent manner (Fig. 4). The rank order and absolute values of the $\mathrm{IC}_{50}$ values of these compounds at inhibiting responses to the two agonists were similar. These values were also similar to the previously reported $K_{i}$ values of these antagonists at $A_{2}$ adenosine receptors (for review, see Jacobsen et al., 1992). Regression analysis of the $\mathrm{IC}_{50}$ values of these antagonists at inhibiting responses to $1 S, 3 R$-ACPD versus inhibiting responses to adenosine yielded a significant correlation, with a correlation coefficient of $0.968(p<0.02)$ (Fig. 5). These data are consistent with the hypothesis that 


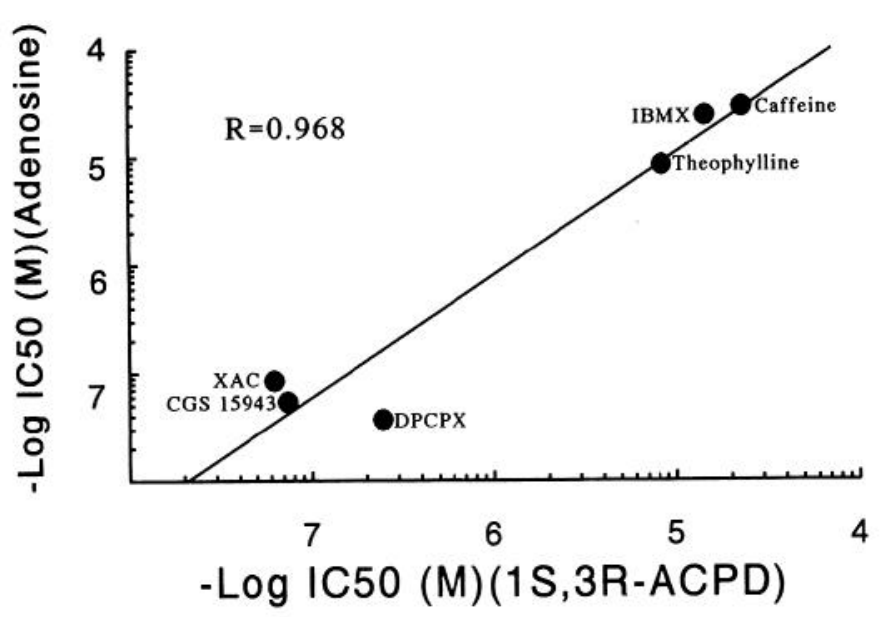

Figure 5. Regression analysis of $\mathrm{IC}_{50}$ values for each antagonist from data shown in Figure 4. Linear regression revealed a correlation coefficient of $+0.968(p<0.02)$.

mGluR-mediated increases in cAMP accumulation are dependent upon activation of $\mathrm{A}_{2 \mathrm{~b}}$ adenosine receptors.

\section{S,3R-ACPD potentiates CAMP responses to endogenous adenosine}

The data presented to this point suggest that activation of $\mathrm{A}_{2}$ receptors by adenosine is necessary for $1 S, 3 R$-ACPD stimulation of cAMP accumulation in the hippocampus. One possible mechanism by which $1 S, 3 R$-ACPD could exert this effect is by increasing release of adenosine from cellular stores. However, previous studies suggest that other EAAs potentiate cAMP responses to adenosine and other agonists (Schmidt et al., 1977; Bruns et al., 1980; Schaad et al., 1990). Thus, it is possible that an mGluR subtype exists that belongs to the class of receptors that potentiate cAMP responses to agonists of other $\mathrm{G}_{s}$-coupled receptors. If so, $1 S, 3 R$-ACPD could increase cAMP accumulation by potentiating the CAMP response to low levels of adenosine that are already present in the extracellular space. If this is the mechanism of $1 S, 3 R$-ACPD stimulation of cAMP accumulation, it is predicted that $1 S, 3 R$-ACPD will potentiate cAMP responses to application of exogenous adenosine and other agonists of receptors that are coupled to adenylate cyclase. Thus, we measured the effect of increasing concentrations of the adenosine receptor agonist 2-CA on cAMP accumulation in the presence and absence of $1 S, 3 R$-ACPD. $1 S, 3 R$-ACPD $(100 \mu \mathrm{M})$ induced a clear potentiation of the cAMP response to all concentrations of 2-CA (Fig. 6). We also examined the effects of $1 S, 3 R$-ACPD on the cAMP responses to agonists of other receptors that are coupled to activation of adenylate cyclase. $1 S, 3 R$ $A C P D$ markedly potentiated the $C A M P$ responses to all agonists tested (Fig. 7). In addition to 2-CA, these included $\mathrm{PGE}_{2}(100$ $\mu \mathrm{M})$, VIP (100 nM), and isoproterenol $(10 \mu \mathrm{M})$.

We next compared the pharmacological profile of $1 S, 3 R$ ACPD-induced increases in basal cAMP accumulation with that of $1 S, 3 R$-ACPD-induced potentiation of 2-CA-stimulated cAMP accumulation to determine if these responses are mediated by the same receptor. As shown in Figure 8, $A$ and $B$, both $1 S, 3 R$ - and $1 S, 3 S$-ACPD stimulate an increase in cAMP over basal and potentiate the response to $50 \mu \mathrm{M} 2-\mathrm{CA}$, while $1 R, 3 S$-ACPD has no effect on basal or 2-CA-stimulated cAMP accumulation. Also, neither $500 \mu \mathrm{M}$ D-AP5 nor $200 \mu \mathrm{M}$ CNQX blocked the $1 S, 3 R$-ACPD-stimulated increases in cAMP accumulation or potentiation of the response to $50 \mu \mathrm{M} 2-\mathrm{CA}$, while

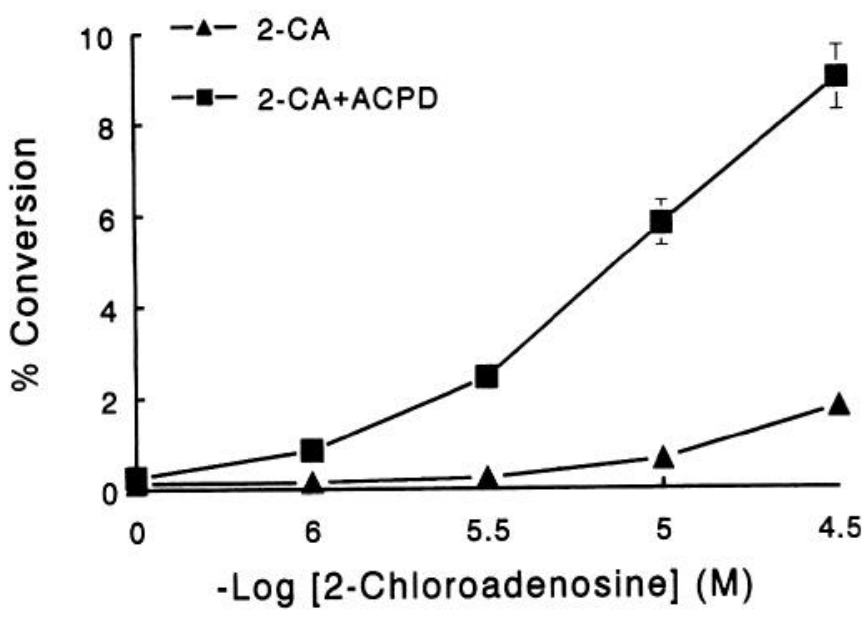

Figure 6. Effect of $100 \mu \mathrm{M} 1 S, 3 R$-ACPD on 2-CA-stimulated cAMP accumulation. Data are expressed as percentage conversion of ${ }^{3} \mathrm{H}$-adenine to ${ }^{3} \mathrm{H}-\mathrm{cAMP}$. Each point represents the mean $( \pm$ SEM) of three separate experiments, each done in triplicate. $A C P D, 1 S, 3 R$-ACPD.

$500 \mu \mathrm{M}$ L-AP3 significantly attenuated both responses (data not shown). These data suggest that both potentiation of responses to 2-CA and increases in basal cAMP are mediated by activation of an mGluR.

It is interesting to note that ADA does not appear to reduce cAMP accumulation to a level below that seen in the absence of added agonists (Fig. 2). This suggests that extracellular adenosine is not present in sufficient concentrations to influence basal cAMP turnover appreciably. This brings into question the hypothesis that the resting extracellular adenosine concentration is high enough to allow a cAMP response to $1 S, 3 R$-ACPD without a $1 S, 3 R$-ACPD-induced increase in adenosine release. To address this issue, we performed an experiment wherein the endogenous adenosine was removed by addition of ADA and then replaced in the form of the ADA-resistant 2-CA at a concentration that does not stimulate increases in basal cAMP accumulation. As shown in Figure 9, application of $\operatorname{ADA}(5 \mathrm{U} / \mathrm{ml})$ abolished the increase in CAMP induced by $1 S, 3 R$-ACPD. Fur-

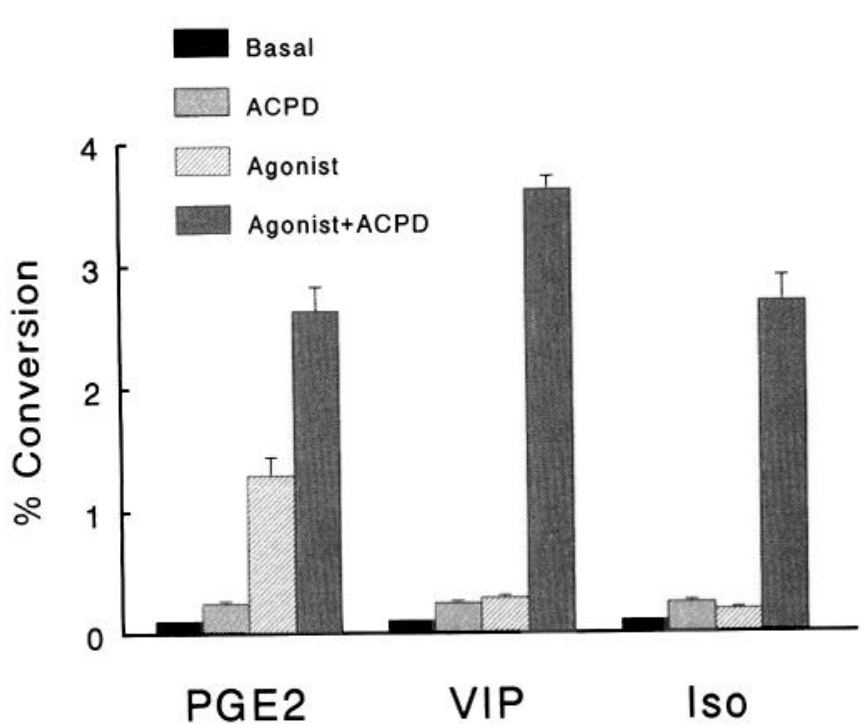

Figure 7. Effect of $100 \mu \mathrm{M} 1 S, 3 R$-ACPD on the cAMP accumulations induced by agonists other than adenosine. Each bar represents the mean $( \pm$ SEM) of three experiments, each done in triplicate. PGE2, prostaglandin $\mathrm{E}_{2}(100 \mu \mathrm{M}) ; V I P$, vasoactive intestinal peptide $(100 \mathrm{~nm}) ;$ Iso, isoproterenol $(10 \mu \mathrm{M})$. 

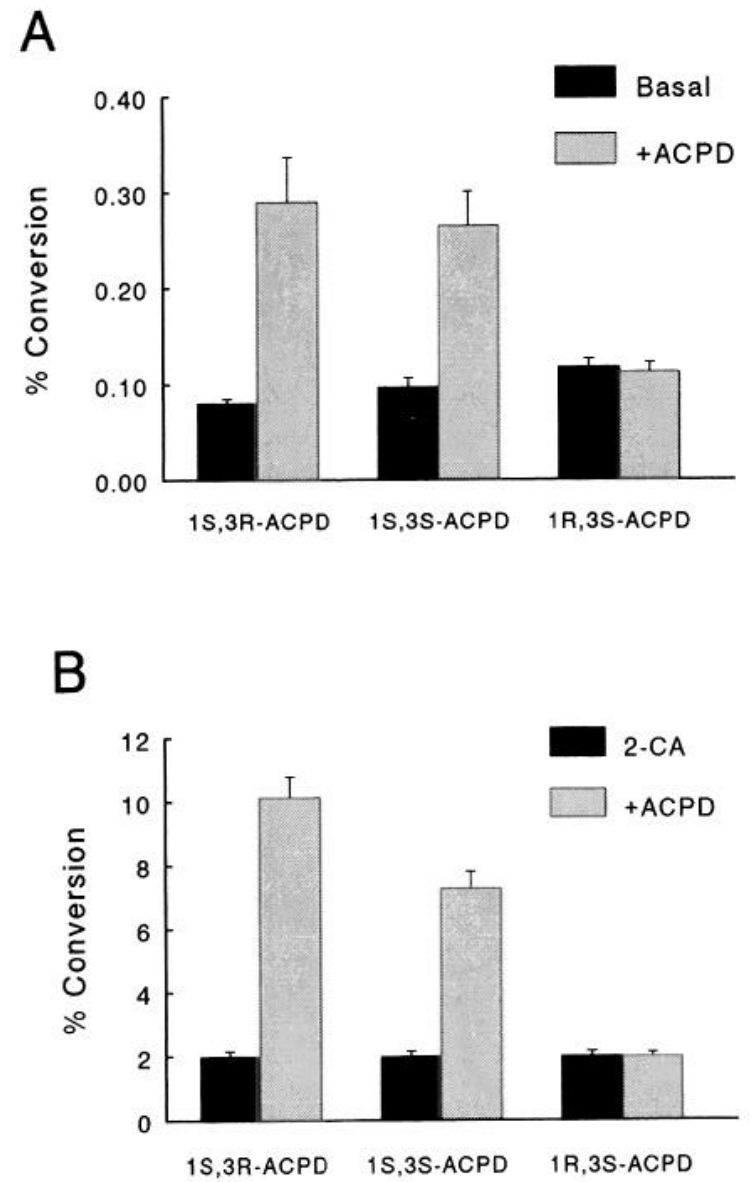

Figure 8. Effects of ACPD isomers on basal $(A)$ and $50 \mu \mathrm{M}$ 2-CA-stimulated $(B)$ cAMP accumulations. Isomers of ACPD were used at a concentration of $100 \mu \mathrm{M}$. Each bar represents the mean ( \pm SEM) of three separate experiments, each done in triplicate.

thermore, 750 nм 2-CA had no effect on cAMP accumulation when added alone. However, when $100 \mu \mathrm{M} 1 S, 3 R$-ACPD was added in the presence of $750 \mathrm{~nm} 2-\mathrm{CA}$, it elicited a response that was similar to that elicited by $100 \mu \mathrm{M} 1 S, 3 R$-ACPD in slices that were not incubated with ADA and 2-CA. (Fig. 9). These data indicate that activation of mGluRs is capable of stimulating an increase in cAMP accumulation to a concentration of adenosine that alone is not capable of stimulating detectable increases in cAMP.

\section{Discussion}

We present evidence for the existence of an mGluR subtype that belongs with the growing number of receptors that interact synergistically with $\mathrm{G}_{s}$-coupled receptors to increase cAMP accumulation. Activation of members of this class of receptors in the absence of other agonists generally has no effect on cAMP accumulation. However, agonists of these receptors markedly potentiate cAMP responses to activation of other receptors that are directly coupled to adenylate cyclase via $\mathrm{G}_{s}$. Receptors that belong to this class include $\alpha_{1}$ adrenergic receptors, $\mathrm{H}_{1}$ histaminergic receptors, and others (Magistretti and Schorderet, 1985; Pilc and Enna, 1986; Johnson and Minneman, 1987; Garbarg and Schwartz, 1988; Schaad et al., 1989). In addition, previous studies have shown that other EAAs increase cAMP responses to other agonists (Schmidt et al., 1977; Bruns et al., 1980; Schaad et al., 1990). However, it was not clear from these earlier studies

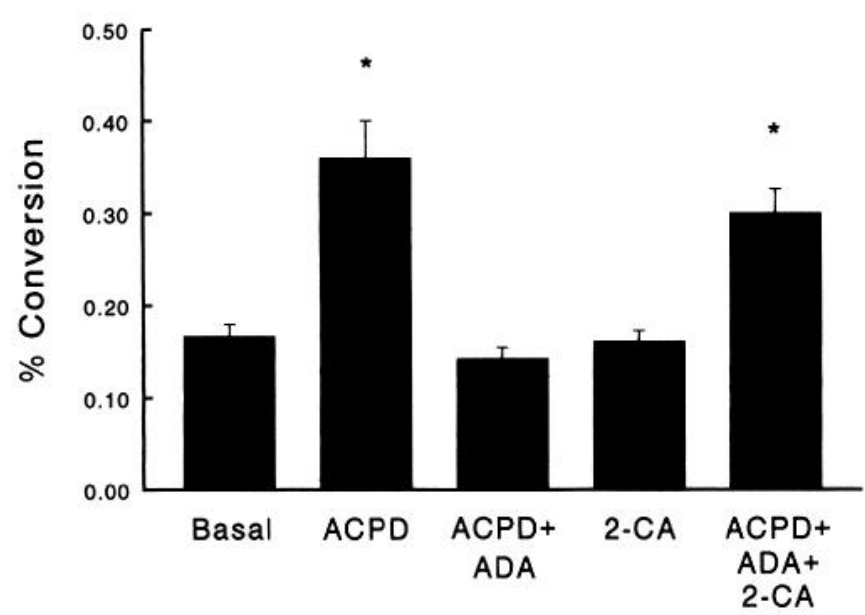

Figure 9. Replacement of endogenous adenosine with a low concentration of 2-CA. Each bar represents the mean $( \pm$ SEM) of three experiments, each done in triplicate. $A C P D, 1 S, 3 R$-ACPD $(100 \mu \mathrm{M}) ; A D A$, adenosine deaminase $(5 \mathrm{U} / \mathrm{ml}) ; 2-C A, 2$-chloroadenosine $(750 \mathrm{~nm}) .{ }^{*}$, $p<0.001$ versus basal. There was no significant difference between $\mathrm{ACPD}$ and ACPD + ADA + 2-CA.

whether this effect was mediated by mGluRs or ionotropic glutamate receptors. We now report that the selective mGluR agonist $1 S, 3 R$-ACPD potentiates cAMP responses to adenosine, $\mathrm{PGE}_{2}$, VIP, and isoproterenol, all of which activate receptors that are positively coupled to adenylate cyclase. This response is not blocked by selective antagonists of ionotropic glutamate receptors but is blocked by the putative mGluR antagonist L-AP3. Thus, it is likely that EAA-induced potentiation of cAMP response is mediated by an mGluR.

At present, the mechanism by which activation of this class of receptor potentiates $\mathrm{G}_{s}$-mediated increases in cAMP accumulation is not known. However, one possible mechanism was recently proposed by Tang and Gilman (1991), who showed in cultured insect ovarian Sf9 cells that although the $\beta \gamma$ subunits of a heterotrimeric $(\alpha \beta \gamma)$ G-protein inhibit type I adenylate cyclase, these same subunits potentiate activation of type II adenylate cyclase by the $\alpha$ subunit of $\mathrm{G}_{s}$. Furthermore, Federman et al. (1992) showed that activation of $\alpha_{2}$ adrenergic receptors increases cAMP levels in cells transfected with the type II adenylate cyclase in a pertussis toxin-sensitive manner. Further studies in their system suggested that this is mediated by generation of free $\beta \gamma$ subunits, which potentiate $\alpha_{s}$-mediated activation of type II adenylate cyclase. Type II adenylate cyclase is abundant in rat brain (Feinstein et al., 1991). We have supplied evidence that $1 S, 3 R$-ACPD-stimulated cAMP accumulation is not mediated by activation of phosphoinositide hydrolysis or protein kinases (Winder and Conn, 1992). Thus, it will be interesting to determine whether the $1 S, 3 R$-ACPD-induced enhancement of cAMP responses to other neurotransmitters is mediated by a similar generation of $\beta \gamma$ subunits and activation of type II adenylate cyclase.

We also present evidence that $1 S, 3 R$-ACPD-stimulated increase in basal cAMP accumulation in hippocampal slices is mediated by potentiation of the cAMP response to endogenous adenosine. We found that $1 S, 3 R$-ACPD-stimulated increase in cAMP levels is blocked by addition of ADA or adenosine receptor antagonists, and is potentiated by the adenosine uptake blocker dipyridamole. Furthermore, analysis of the $\mathrm{IC}_{50}$ values of various adenosine receptor antagonists at inhibiting $1 S, 3 R$ - 
ACPD-stimulated cAMP accumulation suggests that this effect is mediated by activation of $\mathrm{A}_{2}$ adenosine receptors. Taken together with previous findings (Bruns et al., 1986; Jarvis and Williams, 1988; Lupica et al., 1990), these data suggest that the cAMP response to $1 S, 3 R-\mathrm{ACPD}$ is dependent on activation of the $A_{2 b}$ adenosine receptor subtype.

Previous studies suggest that adenosine also plays a role in mediating the effects of glutamate and other EAAs on cAMP accumulation in brain slices. It was concluded in these earlier studies that the EAAs tested stimulated cAMP formation indirectly through release of adenosine (Schmidt et al., 1977; Bruns et al., 1980). We performed studies to determine whether the IS,3R-ACPD-stimulated increase in basal cAMP accumulation is mediated by an increase in adenosine release or potentiation of responses to adenosine that is already present in the extracellular space. If potentiation of the cAMP response to adenosine is sufficient to account for $1 S, 3 R$-ACPD-stimulated increases in basal cAMP accumulation, we would predict $1 S, 3 R$ $A C P D$ could potentiate the response to low concentrations of adenosine that do not elicit a detectable cAMP response in the absence of mGluR agonists (Delapp and Eckols, 1992). This potentiation should result in a detectable cAMP response of a magnitude similar to that normally elicited by $1 S, 3 R$-ACPD. Thus, we performed an experiment in which the cAMP response to $1 S, 3 R$-ACPD was abolished by removal of endogenous adenosine with ADA. We then replaced the endogenous adenosine with 2-CA, an adenosine analog that is not a substrate for ADA. Extracellular adenosine concentrations in hippocampal slices have been estimated to be in the range of $500 \mathrm{nM}$ to $1 \mu \mathrm{M}$ (Fredholm et al., 1984). Adenosine and 2-CA have virtually identical affinities $A_{2}$ adenosine receptors (Bazil and Minneman, 1986; Bruns et al., 1986). Therefore, we replaced endogenous adenosine with $750 \mathrm{~nm}$ 2-CA. This concentration of 2-CA had no detectable effect on cAMP accumulation when added alone. However, in ADA-treated slices, this low concentration of 2-CA completely restored the ability of $1 S, 3 R$-ACPD to stimulate increases in cAMP accumulation. Under these conditions, $1 S, 3 R$ ACPD could not exert its effect by stimulating adenosine release. Thus, potentiation of responses to low levels of endogenous adenosine could entirely account for $1 S, 3 R$-ACPD-stimulated increases in cAMP accumulation in untreated slices. Consistent with this hypothesis, we previously reported that $1 S, 3 R$ ACPD-stimulated increases in CAMP accumulation are not blocked by concentrations of TTX that completely block cell firing (Winder and Conn, 1992), suggesting that the response to $1 S, 3 R$-ACPD is not likely to be mediated by depolarizationinduced adenosine release.

Although our data do not entirely rule out the possibility that $1 S, 3 R$-ACPD induces a slight increase in adenosine release, it is possible that the pool of extracellular adenosine is sufficient to allow stimulation of increases in CAMP levels upon activation of mGluRs. However, it should be noted that studies by Hoehn and White $(1990 \mathrm{a}, \mathrm{b})$ show that other EAAs evoke adenosine release in rat cortical slices. Thus, under normal conditions, glutamate's actions on ionotropic and metabotropic receptors could act synergistically to increase cAMP levels by increasing adenosine release and potentiating the cAMP response to adenosine receptor activation.

To date, stimulation of mGluRs has been shown to activate at least four signal transduction mechanisms in rat hippocampal slices. In addition to the increases in cAMP accumulation reported here, these include increased phosphoinositide hydro- lysis (for review, see Schoepp et al., 1990; Conn and Desai, 1991), inhibition of forskolin-stimulated cAMP accumulation (Cartmell et al., 1992; Schoepp et al., 1992), and inhibition of a calcium conductance (Lester and Jahr, 1990). Furthermore, activation of mGluRs elicits a variety of electrophysiological effects in rat hippocampal slices. For example, trans-ACPD depolarizes pyramidal cells with an accompanying increase in input resistance, blocks spike frequency adaptation (Charpak et al., 1990; Charpak and Gahwiler, 1991; Desai and Conn, 1991), broadens the action potentials (Hu and Storm, 1991), and decreases both inhibitory (Desai and Conn, 1991) and excitatory (Baskys and Malenka, 1991) synaptic transmission. In addition, mGluRs in the hippocampus may play an important role in long-term potentiation (McGuinness et al., 1991; Otani and Ben-Ari, 1991) and epileptogenesis (Iadorola et al., 1986; Sacaan and Schoepp, in press). In future studies, it will be important to determine which mGluR subtypes and corresponding second messenger systems mediate these responses to mGluR activation

\section{References}

Aramori I, Nakanishi S (1992) Signal transduction and pharmacological characteristics of a metabotropic glutamate receptor, mGluR1, in transfected CHO cells. Neuron 8:757-765.

Baskys A, Malenka RC (1991) Agonists at metabotropic glutamate receptors presynaptically inhibit EPSCs in neonatal rat hippocampus. J Physiol (Lond) 444:687-701.

Bazil CW, Minneman KP (1986) An investigation of the low intrinsic activity of adenosine and its analogs at low affinity (A2) adenosine receptors in rat cerebral cortex. J Neurochem 47:547-553.

Bruns RF, Pons F, Daly JW (1980) Glutamate- and veratridine-elicited accumulations of cyclic AMP in brain slices: a role for factors which potentiate adenosine-responsive systems. Brain Res 189: 550-555.

Bruns RF, Daly JW, Pugsley TA (1986) Characterization of the A2 receptor labelled by [ $\left.{ }^{3} \mathrm{H}\right]-\mathrm{NECA}$ in rat striatal membranes. Mol Pharmacol 29:331-346.

Cartmell J, Kemp JA, Alexander SPH, Hill SJ, Kendall DA (1992) Inhibition of forskolin-stimulated cyclic AMP formation by 1-aminocyclopentane-trans-1,3-dicarboxylate in guinea-pig cerebral cortical slices. J Neurochem 58:1964-1966.

Charpak S, Gahwiler BH (1991) Glutamate mediates a slow synaptic response in hippocampal slice cultures. Proc R Soc Lond [Biol] 243: 221-226.

Charpak S, Gahwiler BH, Do KQ, Knopfel T (1990) Potassium conductances in hippocampal neurons blocked by excitatory amino-acid transmitters. Nature 347:765-767.

Choi OH, Shamim MT, Padgett WL, Daly JW (1988) Caffeine and theophylline analogues: correlation of behavioral effects with activity as adenosine receptor antagonists and as phosphodiesterase inhibitors. Life Sci 43:387-398.

Collingridge GL, Lester RAJ (1989) Excitatory amino acid receptors in the vertebrate central nervous system. Pharmacol Rev 40:143-210.

Conn PJ, Desai MA (1991) Pharmacology and physiology of metabotropic glutamate receptors in mammalian central nervous system. Drug Dev Res 24:207-229.

DeLapp NW, Eckols K (1992) Forskolin stimulation of cyclic AMP accumulation in rat brain cortex slices is markedly enhanced by endogenous adenosine. J Neurochem 58:237-242.

Desai MA, Conn PJ (1990) Selective activation of phosphoinositide hydrolysis by a rigid analogue of glutamate. Neurosci Lett 109:157-162.

Desai MA, Conn PJ (1991) Excitatory effects of ACPD receptor activation in the hippocampus are mediated by direct effects on pyramidal cells and blockade of synaptic inhibition. J Neurophysiol 66 $40-52$.

Federman AD, Conklin BR, Schrader KA, Reed RR, Bourne HR (1992) Hormonal stimulation of adenylyl cyclase through $G_{i}$-protein $\beta \gamma$ subunits. Nature 356:159-161.

Feinstein PG, Schrader KA, Bakalyar HA, Tang W, Krupinski J, Gilman AG, Reed RR (1991) Molecular cloning and characterization of a 
$\mathrm{Ca}^{2+} /$ calmodulin-insensitive adenylyl cyclase from rat brain. Proc Natl Acad Sci USA 88:10173-10177.

Fredholm BB, Dunwiddie TV, Bergman B, Lindstrom K (1984) Levels of adenosine and adenine nucleotides in slices of rat hippocampus. Brain Res 295:127-136.

Garbarg M, Schwartz J-C (1988) Synergism between histamine $\mathrm{H}_{1}$ and $\mathrm{H}_{2}$-receptors in the cAMP response in guinea pig brain slices: effects of phorbol esters and calcium. Mol Pharmacol 33:36-43.

Hoehn K, White TD (1990a) $N$-methyl-D-aspartate, kainate, and quisqualate release endogenous adenosine from rat cortical slices. Neuroscience 39:441-450.

Hoehn K, White TD (1990b) Role of excitatory amino acid receptors in $\mathrm{K}^{+}$- and glutamate-evoked release of endogenous adenosine from rat cortical slices. J Neurochem 54:256-265.

Houamed KM, Kuijper JL, Gilbert TL, Haldeman BA, O'Hara PJ, Mulvihill ER, Almers W, Hagen FS (1991) Cloning, expression, and gene structure of a $G$ protein-coupled glutamate receptor from rat brain. Science 252:1318-1321.

Hu G-Y, Storm JF (1991) Excitatory amino acids acting on metabotropic glutamate receptors broaden the action potential in hippocampal neurons. Brain Res 568:339-344.

Iadorola MJ, Nicoletti F, Naranjo JR, Putnam F, Costa E (1986) Kindling enhances the stimulation of inositol phospholipid hydrolysis elicited by ibotenic acid in rat hippocampal slices. Brain Res 374: 174-178.

Jacobsen KA, Philip JM, Williams M (1992) Adenosine receptors: pharmacology, structure-activity relationships, and therapeutic potential. J Med Chem 35:407-422.

Jarvis MF, Williams M (1988) Differences in adenosine A-1 and A-2 receptor density revealed by autoradiography in methylxanthine-sensitive and insensitive mice. Pharmacol Biochem Behav 30:707-714.

Johnson RD, Minneman KP (1987) Differentiation of $\alpha_{1}$-adrenergic receptors linked to phosphatidylinositol turnover and cAMP accumulation in rat brain. Mol Pharmacol 31:239-246.

Lester RAJ, Jahr CE (1990) Quisqualate receptor-mediated depression of calcium currents in hippocampal neurons. Neuron 4:741-749.

Lupica CR, Cass WA, Zahniser NR, Dunwiddie TV (1990) Effects of the selective adenosine A2 receptor agonist CGS 21680 on in vitro electrophysiology, cAMP formation and dopamine release in rat hippocampus and striatum. J Pharmacol Exp Ther 252:1134-1141.

Magistretti PJ, Schorderet M (1985) Norepinephrine and histamine potentiate the increases in cyclic adenosine $3^{\prime}: 5^{\prime}$-monophosphate elicited by vasoactive intestinal polypeptide in mouse cerebral cortical slices: mediation by $\alpha_{1}$-adrenergic and $\mathrm{H}_{1}$-histaminergic receptors. J Neurosci 5:362-368.

Masu M, Tanabe Y, Tsuchida K, Shigemoto R, Nakanishi S (1991) Sequence and expression of a metabotropic glutamate receptor. Nature 349:760-765.

McGuinness N, Anwyl R, Rowan M (1991) The effects of trans-ACPD on long-term potentiation in the rat hippocampal slice. Neuroreport $2: 688-690$
Monaghan DT, Bridges RJ, Cotman CW (1989) The excitatory amino acid receptors: their classes, pharmacology, and distinct properties in the function of the central nervous system. Annu Rev Pharmacol Toxicol 29:365-402.

Olah ME, Stiles GL (1992) Adenosine receptors. Annu Rev Physiol $54: 211-225$

Otani S, Ben-Ari Y (1991) Metabotropic receptor-mediated long-term potentiation in rat hippocampal slices. Eur J Pharmacol 205:325-326.

Palmer E, Monaghan DT, Cotman CW (1989) Trans-ACPD, a selective agonist of the phosphoinositide-coupled excitatory amino acid receptor. Eur J Pharmacol 166:585-587.

Pilc A, Enna SJ (1986) Activation of alpha-2 adrenergic receptors augments neurotransmitter-stimulated cyclic AMP accumulation in rat brain cerebral cortical slices. J Pharmacol Exp Ther 237:725-730.

Sacaan AI, Schoepp DD (1992) Activation of hippocampal metabotropic excitatory amino acid receptors leads to seizures and neuronal damage. Neurosci Lett 139:77-82.

Schaad NC, Schorderet M, Magistretti PJ (1989) Accumulation of cyclic AMP elicited by vasoactive intestinal peptide is potentiated by noradrenaline, histamine, adenosine, baclofen, phorbol esters, and ouabain in mouse cerebral cortical slices: studies on the role of arachidonic acid metabolites and protein kinase C. J Neurochem 53: 1941-1951.

Schaad NC, Schorderet M, Magistretti PJ (1990) Modulation of VIPstimulated cAMP formation by excitatory amino acids in mouse cerebral cortex. Eur J Neurosci 2:525-533.

Schmidt MJ, Thornberry JF, Molloy BB (1977) Effects of kainate and other glutamate analogues on cyclic nucleotide accumulation in slices of rat cerebellum. Brain Res 121:182-189.

Schoepp D, Bockaert J, Sladeczek F (1990) Pharmacology and functional characteristics of metabotropic excitatory amino acid receptors. Trends Pharmacol Sci 1 1:508-515.

Schoepp DD, Johnson BG, Monn JA (1992) Inhibition of cyclic AMP formation by a selective metabotropic glutamate receptor agonist. J Neurochem 58:1184-1186.

Shimizu H, Crevelling CR, Daly JW (1969) A radioisotopic method for measuring the formation of adenosine $3^{\prime}, 5^{\prime}$-cyclic monophosphate in incubated slices in brain. J Neurochem 16:1609-1619.

Shimizu H, Ichishita H, Odagiri H (1974) Stimulated formation of cyclic adenosine $3^{\prime}: 5^{\prime}$-monophosphate by aspartate and glutamate in cerebral cortical slices of guinea pig. J Biol Chem 249:5955-5962.

Tanabe Y, Masu M, Ishii T, Shigemoto R, Nakanishi S (1992) A family of metabotropic glutamate receptors. Neuron 8:1-20.

Tang W-J, Gilman AG (1991) Type-specific regulation of adenylyl cyclase by $G$ protein $\beta \gamma$ subunits. Science 254:1500-1503.

Winder DW, Conn PJ (1992) Activation of metabotropic glutamate receptors in the hippocampus increases cyclic AMP accumulation. J Neurochem 59:375-378. 